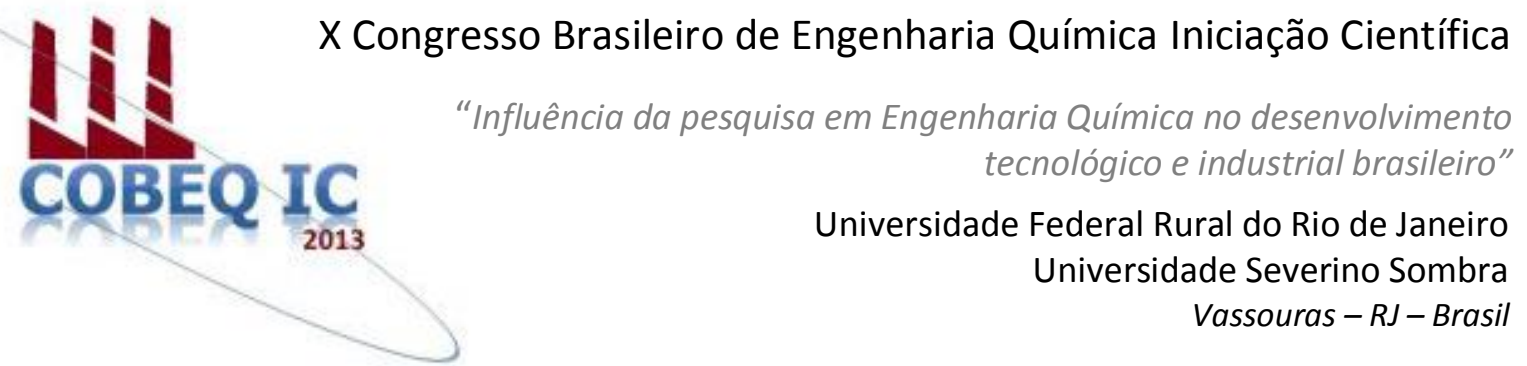

\title{
ESTUDO DAS PROPRIEDADES FÍSICAS E TÉRMICAS DE MATERIAIS COMPÓSITOS DE LIGNINA E POLIESTIRENO
}

\author{
GUIMARÃES ${ }^{* 1}$, H. R.; TANNOUS ${ }^{2}$, K. \\ ${ }^{1}$ Aluno da FEQ/UNICAMP $\quad{ }^{2}$ Professora da FEQ/UNICAMP \\ Faculdade de Engenharia Química - Universidade Estadual de Campinas \\ Cidade Universitária "Zeferino Vaz" \\ Av. Albert Einstein, 500 - CEP 13083-852 - Campinas - SP - Brasil \\ email: katia@feq.unicamp.br
}

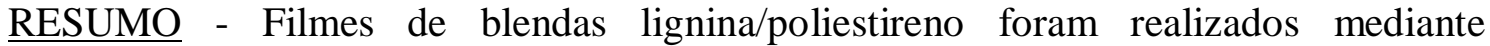
evaporação de solvente (tetrahidrofurano) nas proporções de 7,5\%,15\% e $30 \%$, lignina/poliestireno. Os filmes foram caracterizados morfologicamente mediante microscopia ótica e microscopia eletrônica de varredura, onde se constatou que com o aumento da concentração de lignina produzem-se filmes mais quebradiços e pouco dissolvidos no polímero. Além disso, os filmes foram submetidos à alta temperatura (até $900{ }^{\circ} \mathrm{C}$ ) a fim de verificar sua decomposição (termogravimetria) e transição vítrea (calorimetria). Com a análise termogravimétrica verificou-se que: a decomposição dos componentes da blenda ocorreu em etapas processuais, indicando que a lignina e o PS não se encontram ligados intimamente; a temperatura máxima de decomposição das blendas foi em torno de $450{ }^{\circ} \mathrm{C}$; o aumento da concentração de lignina diminuiu a taxa de decomposição dos filmes. Pela análise calorimétrica diferencial de varredura, observou-se que há apenas uma temperatura de transição vítrea para cada blenda, sendo estes: $87{ }^{\circ} \mathrm{C}$ para o filme de $7,5 \%$ lignina/PS, $88^{\circ} \mathrm{C}$ para $15 \%$ lignina/PS e $95{ }^{\circ} \mathrm{C}$ para $30 \%$ lignina/PS. A presença de apenas uma temperatura de transição vítrea indica uma boa miscibilidade entre os componentes.
\end{abstract}

Palavras chave: termogravimetria, calorimetria, filmes poliméricos

\section{INTRODUÇÃO}

A lignina é um polímero natural abundante nas plantas vasculares $(15-30 \%$ da composição) cuja função é: auxiliar no transporte de água e nutrientes; é responsável pela resistência mecânica dos vegetais; servir como proteção contra ataque de microorganismos (Bianchi, 1999; Camargo, 2009).

Este componente é uma macromolécula formada por unidades fenilpropanóides ligadas entre si. As três principais unidades estruturais são: p-hidroxifenil, guaiacil e siringil. Essas unidades unem-se através de ligações éter e carbono (Bianchi, 1999). A estrutura da lignina pode variar bastante dependendo tanto do tipo de planta, quanto das condições às quais se encontra como clima da região e sua etapa de desenvolvimento.

Basicamente, nas folhosas (ex.: eucalip- 
to) há uma predominância das unidades guaiacil e siringil, enquanto em coníferas (ex.: pinus), a lignina é composta principalmente de unidades guaiacil. Já as gramíneas possuem proporções significativas de p-hidroxifenil (Benar, 1996).

A grande fonte de lignina vem da indústria de papel, onde esta é um dos principais subprodutos da polpação da madeira. Como a lignina confere resistência e cor escura ao papel, faz-se necessário extraí-la dependendo da finalidade do produto. $\mathrm{O}$ método mais comum de polpação é o método Kraft, ou "Sulfato", que utiliza $\mathrm{Na}_{2} \mathrm{~S}$ e $\mathrm{NaOH}$ para separar a lignina da celulose por meio de hidrólise. A maior parte desse resíduo de lignina é queimada no processo de polpação, gerando energia para a planta industrial (Camargo, 2009).

Stewart (2008) analisou diversas aplicabilidades para a lignina. Apesar de sua heterogeneidade ser um fator limitante, a lignina é uma boa candidata para aplicações em resinas fenólicas. Outras aplicações, da lignina como agente reticulante, são em resinas epóxi, adesivos e poliolefinas.

A lignina vem sendo largamente estudada quanto a sua utilidade em blendas poliméricas. Camargo (2009) estudou diferentes blendas de lignina com PHBV (poli3-hidroxibutirato-3-hidroxivalerato) em uma proporção de $50 \%$ (massa lignina/massa polímero). Os autores realizaram filmes e corpos de prova, preparados via extrusora e biodegradação das blendas resultantes. Como resultado, o autor obteve uma imiscibilidade da mistura, no entanto houve um aumento da biodegradação das blendas.

Outro estudo realizado foi de Kadla e Kubo (2004), onde os autores analisaram as interações intermoleculares em blendas de lignina, em diferentes proporções, com PVA (alcool polivinílico), PP (polipropileno), PET (politereftalato de etileno) e PEO (óxido de polietileno). As blendas foram consideradas miscíveis nos casos do PET e do PEO. No caso do PEO, justificou-se essa miscibilidade pelas interações das ligações de hidrogênio entre os grupos hidroxila da lignina e os oxigênios dos grupos éter, enquanto a miscibilidade lignina/PET acontece, apesar de não haver ligações fortes de hidrogênio entre as moléculas.

Nas análises de Pouteau et al. (2004), filmes foram realizados mediante extrusão da lignina com diferentes polímeros, sendo estes: polietileno de baixa densidade (PEBD), polipropileno (PP), óxido de polimetileno (PMO), óxido de polietileno (PEO), poliestireno (PS), poliacrilonitrila (PAN), policloreto de vinila (PVC), e PVC plastificado, acetato de polivinila (PVAc), poli(3hidroxibutirato-co-3-hidroxivalerato (PHBV), poli(adipato de etieleno (PEA) e polibutileno succinato co-adipato (PBSA), tendo suas compatibilidades observadas através de micrografias. Os autores constataram as melhores compatibilidades para o PS, PBSA, PVC e PEA, superando inclusive o PEO verificado no estudo anterior. No entanto para o PS, com o aumento da quantidade de lignina, houve aumento na compatibilidade, diferente dos outros polímeros.

\section{MATERIAIS E MÉTODOS}

\section{Materiais}

A amostra de lignina foi cedida pela empresa Suzano Papel e Celulose, extraída da madeira Eucaliptus Grandis.

O diâmetro médio das partículas da amostra de lignina, bem como sua distribuição granulométrica, foi obtido por difração a laser Mastersizer S (modelo S-MAM 5005 da marca Malvern, Reino Unido). A análise foi feita com a amostra dispersa em etanol. Três diâmetros médios puderam ser determinados a partir da distribuição granulométrica: diâmetro relativo ao volume igual a 231,32 $\mu \mathrm{m}$; diâmetro relativo à área superficial igual 30,44 $\mu \mathrm{m}$; e diâmetro com $50 \%$ das partículas menores que $188,21 \mu \mathrm{m}$.

Sua massa específica real foi determinada utilizando um picnômetro de gás de Hélio (marca Micromeritics, modelo AccuPyc $1330 \mathrm{~V} 2.02$ ), onde o volume da amostra foi determinada pela variação de pressão de um gás com volume conhecido. A massa específica real da amostra, e respectivo desvio padrão, foram de $(1364,7 \pm 0,0002)$ $\mathrm{kg} / \mathrm{m}^{3}$.

Com relação ao poliestireno, utilizou-se diâmetro médio de Sauter, medido por peneiramento, e massa específica aparente por 
deslocamento de líquido (picnometria) usando água como meio líquido. O diâmetro médio foi de $(3,98 \pm 0,02) \mathrm{mm}$ e massa específica de $(1003 \pm 2) \mathrm{kg} / \mathrm{m}^{3}$.

\section{Preparo dos filmes}

Os filmes foram elaborados pelo processo de evaporação de solvente conforme: PS puro; blendas de lignina e poliestireno nas proporções de 7,5\%,15\% e $30 \%$ (massa lignina/massa de PS).

Primeiramente, foi utilizado tetrahidrofurano (THF) para solubilizar o poliestireno e dispersar a lignina, em frascos separados, obtendo soluções de concentração $1 \mathrm{~g}$ sólido/10 ml THF. Estas soluções foram deixadas em repouso, tampadas por 24 horas para evitar evaporação do solvente e garantir que todo o sólido fosse dissolvido.

As dispersões de lignina/THF e soluções de PS/THF foram então misturadas nas quantidades adequadas para a obtenção dos filmes, sob agitação magnética por uma hora, e em seguida despejadas em moldes de silicone, deixadas tampadas por uma placa de Petri.

Os moldes permaneceram tampados pela placa por uma semana, para evitar a evaporação rápida do solvente, que poderia causar bolhas em excesso nos filmes.

\section{Caracterização Morfológica}

Para a análise da superfície e estrutura morfológica dos filmes foi utilizado o método da Microscopia Eletrônica de Varredura (MEV). O equipamento foi da marca Leica LEO 440i (Cambridge, Inglaterra). Para a cobertura de ouro das amostras, utilizou-se um metalizador Polaron, modelo Sputtter Coater SC 7620 (Uckfield, Inglaterra). A análise foi feita tanto para a superfície das amostras quanto para as fraturas dos filmes depois de imersos em nitrogênio líquido.

Para complementar as análises, foram realizadas micrografias da superfície dos filmes por microscópio óptico (MO) da marca Leica, modelo DMLM (Cambridge, Inglaterra), sem a utilização de tingimento.

\section{Caracterização Térmica}

As amostras de lignina, PS natural e as blendas, foram submetidas à termodecomposição através da técnica de termogra- vimetria (TGA), realizado em um equipamento Shimadzu TGA-50 (Japão), com razão de aquecimento de $10^{\circ} \mathrm{C} / \mathrm{min}$ em atmosfera de nitrogênio, vazão de $50 \mathrm{ml} / \mathrm{min}$, com temperatura variável entre $25^{\circ} \mathrm{C}$ e $900{ }^{\circ} \mathrm{C}$.

Também para as mesmas amostras, mediu-se a capacidade calorífica através da transição vítrea mediante um calorímetro diferencial de varredura (DSC), da marca Shimadzu DSC-50 (Japão). Um aquecimento inicial (até $200^{\circ} \mathrm{C}$ ) com nitrogênio $\left(10^{\circ} \mathrm{C} / \mathrm{min}\right.$, $50 \mathrm{ml} / \mathrm{min}$ ) foi realizado a fim de eliminar o histórico térmico da amostra (Camargo, 2009). Após o resfriamento da mesma, procedeu-se com o aquecimento de $10^{\circ} \mathrm{C} / \mathrm{min}$ com atmosfera de nitrogênio a $50 \mathrm{ml} / \mathrm{min}$ até $400^{\circ} \mathrm{C}$.

\section{RESULTADOS E DISCUSSÃO}

\section{Caracterização morfológica}

Na Figura 1, observam-se as micrografias aplicando a técnica de criofratura com nitrogênio líquido sobre filmes de PS puro e blendas.
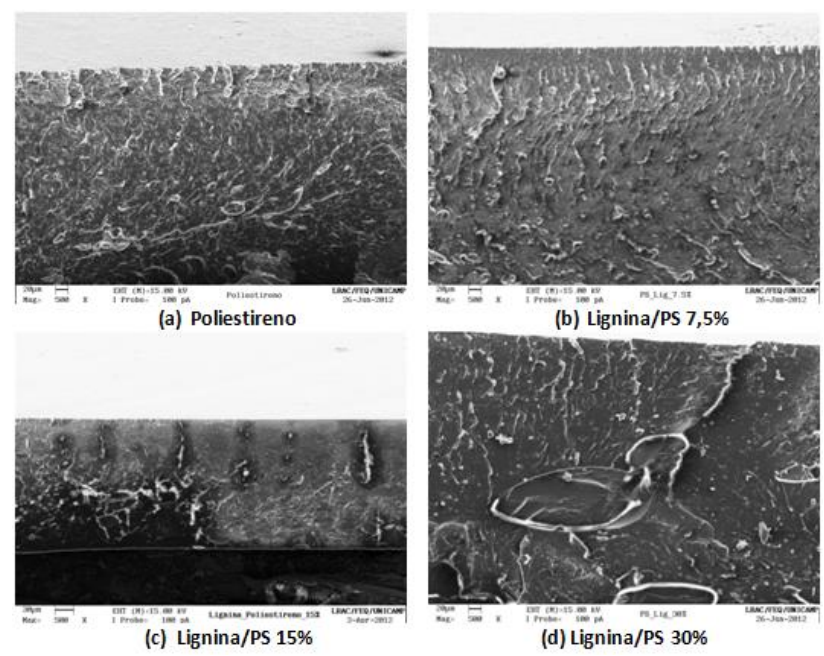

Figura 1: MEV de filmes criofraturados

É possível observar que com o aumento da concentração de lignina (Figuras 1a à 1d), a superfície torna-se irregular, com maiores fissuras. No filme com $30 \%$ lignina/PS (Figura 1d), além de maiores irregularidades, nota-se provavelmente aglomerados de lignina não dispersos no polímero, devido à alta concentração de lignina.

Para ajudar na observação desse fenômeno, na Figura 2, compararam-se as 
imagens de MEV e MO da superfície dos filmes para as diferentes proporções.

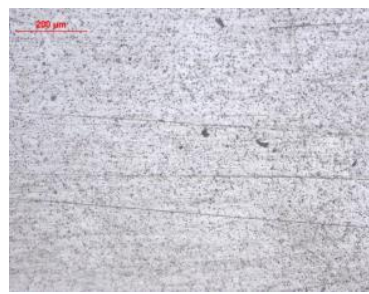

MO ampliação de 100X

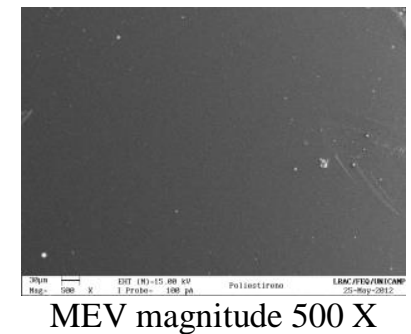

(a) Filme de poliestireno puro

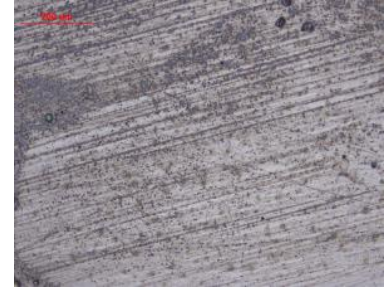

MO ampliação de 100X

(b) Filme de Lignina/PS - 7,5\%

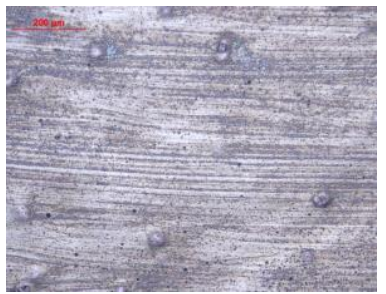

MO ampliação de $100 \mathrm{X}$

(c) Filme de Lignina/PS - 15\%

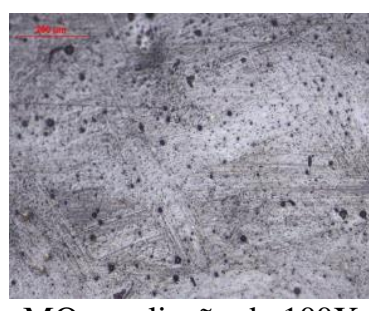

MO ampliação de $100 \mathrm{X}$
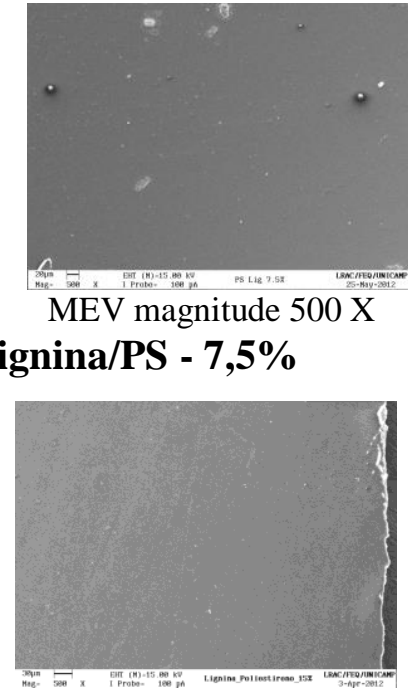

MEV magnitude $500 \mathrm{X}$

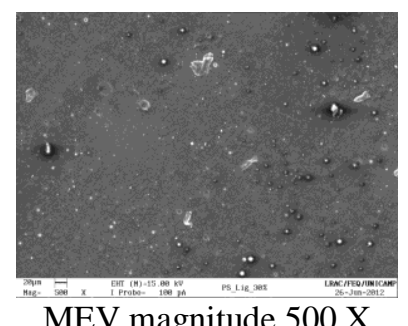

(d) Filme de Lignina/PS - 30\%

Figura 2: Imagens da superfície dos filmes nas diferentes blendas

Com relação às proporções 7,5\% e $15 \%$ (Figuras $2 \mathrm{~b}$ e $2 \mathrm{~d}$ ) pode-se dizer que o filme com $15 \%$ possui menos aglomerados que o filme com 7,5\%. Apesar de ser um resultado estranho partindo-se do pressuposto que maiores proporções geram mais aglomerados, Pouteau [2004] encontrou dados semelhantes, observando que a compatibilidade da lignina no PS melhora com o aumento da concentração até um valor limite desta, diferente de outros polímeros testados.

Para o filme com $30 \%$ lignina/PS, verifica-se a presença de grandes aglomerados de lignina, indicando que a blenda passou o limite da miscibilidade.

A presença de bolhas (Figura 1d) pode dificultar a comparação entre os filmes, sendo dependente do modo de preparo das amostras e da evaporação do solvente.

\section{Caracterização Térmica}

$\mathrm{Na}$ Figura 3, têm-se as curvas termogravimétricas das diferentes amostras. Nota-se que o filme de PS apresenta comportamento diferente do PS natural, possivelmente devido a espessura do filme com relação ao material granulado, causando diferentes reações de decomposições.

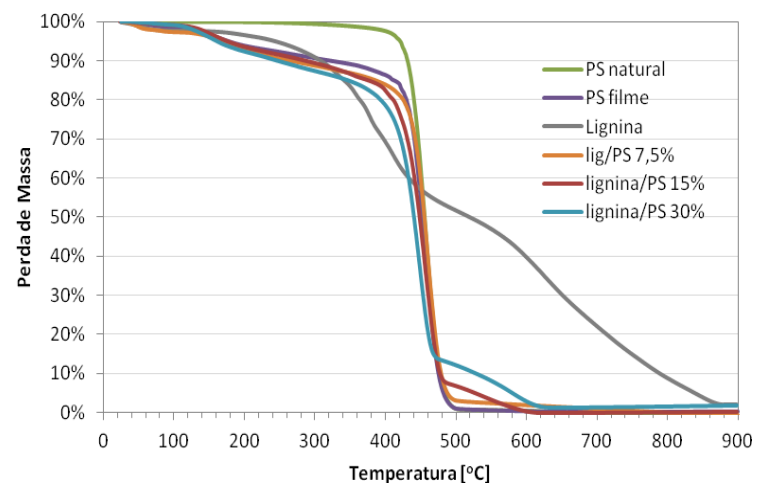

Figura 3: TGA das amostras

Com o aumento da concentração de lignina, a curva termogravimétrica tende cada vez mais à curva da lignina pura, principalmente até a temperatura de $450{ }^{\circ} \mathrm{C}$.

A degradação da lignina passa a ter início à temperaturas mais baixas, por volta de $200^{\circ} \mathrm{C}$, referente à primeira etapa, correspondente a quebra das ligações entre as unidades, com liberação de fenóis.

A segunda etapa de degradação da lignina, referente à decomposição dos anéis aromáticos de sua estrutura, acontece no intervalo de 480-620 ${ }^{\circ} \mathrm{C}$. Entre $480-500{ }^{\circ} \mathrm{C}$ ocorre a perda de massa, referente a degradação do PS, sendo uma queda brusca, como nota-se pela curva do PS natural. Porém, no caso das blendas essa curva é mais suave, prolongando-se até temperaturas acima de $600{ }^{\circ} \mathrm{C}$, graças a degradação da lignina.

Sendo assim, com o aumento da concentração de lignina há também um aumento da temperatura final de decomposição. 
$\mathrm{Na}$ Figura 4, representam-se as curvas derivativas (DrTGA) da variação de massa por tempo em função da temperatura. Nota-se que o aumento da proporção de lignina acompanha uma diminuição na taxa de massa remanescente. Além disso, a temperatura de máxima degradação dos filmes, para todas as amostras, foi aproximadamente $450{ }^{\circ} \mathrm{C}$.

Com base nas Figuras 3 e 4, nota-se que a mistura lignina/PS não interage no sentido de formar um novo composto, já que a decomposição dessa mistura acontece em etapas deferentes, decompondo-se independentemente.

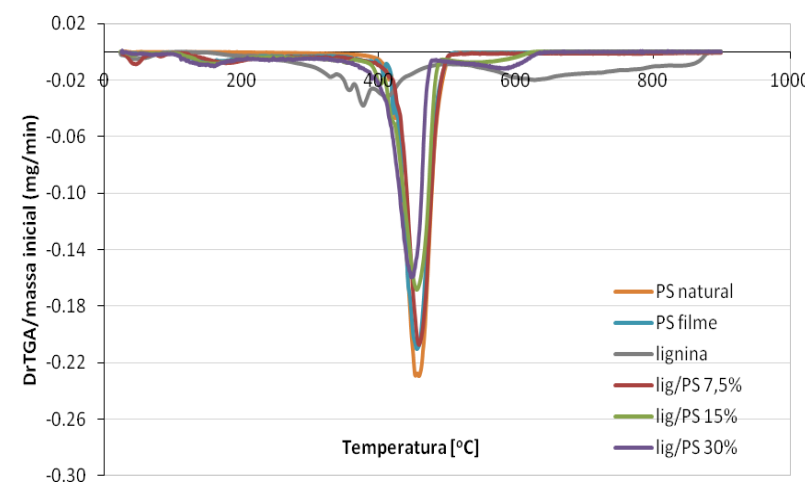

Figura 4: DrTGA das amostras em função da temperatura

Na Figura 5, pode-se observar as curvas de calorimetria das diferentes amostras até $400{ }^{\circ} \mathrm{C}$.

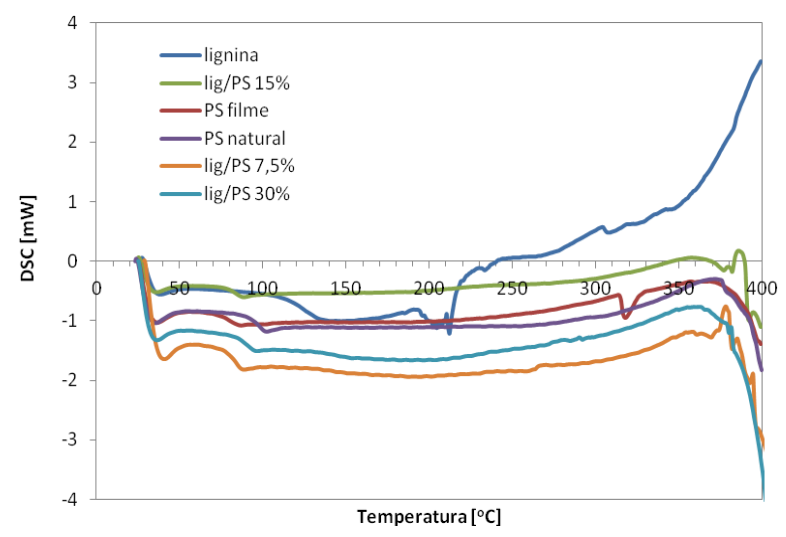

Figura 5: DSC das amostras

Como uma análise mais geral, é possível observar que o comportamento dos filmes de poliestireno segue a mesma tendência, com uma queda inicial até por volta de $40{ }^{\circ} \mathrm{C}$, indicando o início do processo e estabilização do equipamento, após o qual as curvas apresentam-se lineares. Em seguida, ocorre então um "degrau" na curva, por volta de $90{ }^{\circ} \mathrm{C}$, indicando mudança da capacidade calorífica da amostra, característica da transição vítrea. As curvas continuam praticamente lineares até aproximarem-se de $400{ }^{\circ} \mathrm{C}$, onde apresentam um pico endotérmico, provavelmente referente à decomposição do material, como visto na análise do TGA.

O comportamento da lignina também é parecido, com a diferença de que sua transição vítrea acontece a temperaturas maiores, por volta de $140^{\circ} \mathrm{C}$. Vale notar que o fenômeno da decomposição pode ser indicado tanto por um pico endotérmico, quanto exotérmico na curva DSC.

Vê-se também que a temperatura de transição vítrea $(\mathrm{Tg})$ da lignina é em torno de $140{ }^{\circ} \mathrm{C}$, valor presente no intervalo de 100 a $150{ }^{\circ} \mathrm{C}$ encontrado na literatura (Tejado et al., 2006).

Para o PS natural, a Tg está em torno de $102{ }^{\circ} \mathrm{C}$ e para o PS filme, essa temperatura é de aproximadamente $86{ }^{\circ} \mathrm{C}$. Segundo a literatura, a Tg do PS é em torno de $100{ }^{\circ} \mathrm{C}$ (Callister, 2003), próxima do valor encontrado para o PS natural. A diferença entre os valores encontrados para o PS filme e o natural pode ser explicada pelo método de obtenção do filme. A transição vítrea é caracterizada pela reorganização das moléculas do material, passando de um estado vítreo para um estado amorfo. Como o PS foi dissolvido para se fazer o filme, suas moléculas apresentam uma organização diferente da apresentada pelo PS granulado. Com essa nova morfologia, a transição dá-se mais facilmente, acontecendo, à uma temperatura mais baixa do que a original.

Com a adição de lignina aos filmes, nota-se que o valor da $\mathrm{Tg}$ muda, sendo em torno de $87^{\circ} \mathrm{C}$ para $7,5 \%, 88{ }^{\circ} \mathrm{C}$ para $15 \%$, e $95{ }^{\circ} \mathrm{C}$ para $30 \%$. Nota-se que, conforme o aumento da concentração de lignina, a $\mathrm{Tg}$ tende a aumentar, aproximando-se do valor da $\mathrm{Tg}$ da lignina, e afastando-se do valor da $\mathrm{Tg}$ do PS puro.

Outro fato observado é que aparentemente, os filmes de PS com lignina possuem apenas uma $\mathrm{Tg}$, indicando ser uma 
boa miscibilidade entre os componentes.

\section{CONCLUSÃO}

Através dos diferentes testes realizados, pode-se dizer que a lignina possui uma boa miscibilidade com o poliestireno, visto pelo fato de só haver uma temperatura de transição vítrea nas blendas. Entretanto, não há uma interação mais profunda, como na formação de ligações intermoleculares, já que a degradação dos filmes deu-se em etapas separadas para o PS e para a lignina. Também, sob a concentração de $30 \%$ lignina/PS, a compatibilidade com o polímero diminuiu.

Para aprofundamento do estudo blendas poliméricas com lignina é indicado: testes com outros polímeros; modificar a obtenção das blendas, a fim de obter um filme de melhor qualidade; utilizar outros métodos para a evaporação do solvente ou a mistura dos polímeros através de uma extrusora, e realização de mais testes (ex.: testes mecânicos) para a análise das propriedades dos corpos de prova.

\section{ABREVIAÇÕES}

DrTGA derivada da curva termogravimétrica

DSC calorimetria diferencial de varredura

MEV microscopia eletrônica de varredura

MO microscopia óptica

PS poliestireno

$\mathrm{Tg}$ temperatura de transição vítrea $\left({ }^{\circ} \mathrm{C}\right)$

TGA análise termogravimétrica

THF tetrahidrofurano

\section{REFERÊNCIAS}

BENAR, P. (1996), Ligninas acetosolv e formacell de eucalipto e de bagaço de cana: Isolamento, fracionamento, caracterização e uso como componente de resinas fenólicas do tipo resol, IQ/UNICAMP, Campinas (tese de doutorado), 114p.

BIANCHI, M. L. (1999). Branqueamento de polpas Kraft com $\mathrm{H}_{2} \mathrm{O}_{2}$ e reação de oxidação de composto modelo de lignina catalisados por polioximetalatos, IQ/UNICAMP, Campinas (tese de doutorado), 104p.
CALLISTER, W. D. (2003); Materials science and engineering: an introduction, editor John Wiley, Nova Iorque, Estados Unidos, 192p.

CAMARGO, F. A. (2009). Obtenção e caracterização das blendas de lignina (sulfonadas, bagaço de cana-deaçúcar, eucalipto) e taninos com o poli(3hidroxibutirato-co-3hidroxivalerato)/

PHBV. FEQ/UNICAMP, Campinas (tese de doutorado), 115p.

KADLA, J. F; KUBO, S. (2004). Lignin-based polymer blends: analysis of intermolecular interactions in lignin-synthetic polymer blends. Composites Part A: Applied Science and Manufacturing, v. 35, n.3, 395-400.

POUTEAU, C.; BAUMBERGER, S; CATHALA, B.; DOLE P. (2004); LigninPolymer blends: evaluation of compatibility by image analysis. Comptes

Rendus Biologies, v. 327, n. 9-10, 935943.

STEWART, D. (2008). Lignin as a base material for materials applications: Chemistry, application and economics. Industrial Crops and Products, v. 27, n. 2, 202-207.

TEJADO, A., PEÑA, C., LABIDI, J., ECHEVERRIA, J.M., MONDRAGON, I., (2007). Physico-chemical characterization of lignins from different sources for use in phenol-formaldehyde resin synthesis. Bioresource Technology, v. 98, n. 8, 1655-1663.

\section{AGRADECIMENTOS}

Agradecimentos aos colegas do LaProM, aos funcionários do LRAC e do LCPP/FEQ pelo auxílio técnico, à Profa. Dra. Ana Rita Morales, a empresa Suzano Papel e Celulose pela doação da lignina e ao $\mathrm{CNPq}$ pela bolsa concedida. 